IIIIIIIIIIIIIIIIIIIIIIIIIIII

ミニレビュー

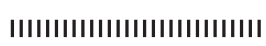

\title{
ピリダリルの創製およびジハロプロペン殺虫剤の展開
}

\author{
池上 宏*, 坂 本 典 保
}

住友化学株式会社 健康・農業関連事業研究所

（2013年11月29日受理）

\section{Discovery of pyridalyl and development of dihalopropene insecticides}

\author{
Hiroshi Ikegami and Noriyasu Sakamoto \\ Health \& Crop Sciences Research Laboratory, Sumitomo Chemical Co., Ltd., \\ 2-1, Takatsukasa 4-chome, Takarazuka, Hyogo 665-8555, Japan
}

Keywords: pyridalyl, insecticide, miticide, dihalopropene.

\section{はじめに}

1990年代初め, 当時農業用殺虫剂の主流を占めていた有 機リン系殺虫剤や合成ピレスロイド殺虫剤に対する各種害虫 の抵抗性の発達が世界各地で顕在化してきていた，そのよう な背景のもと, 住友化学では, チョウ目害虫に優れた殺虫活 性を示し，既存の殺虫剤とは異なる作用機構を有すると考え られる新しいケミカルクラスであるジハロプロペン殺虫剂を 独自に創製した。そのリード化合物の殺虫活性は微弱なもの であったが，そこからいくつものブレークスルーを経て，ピ

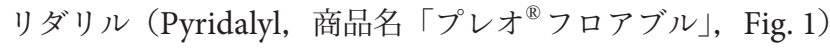
を見出すに至った．本剤は，チョウ目やアザミウマ目害虫に 対して優れた殺虫活性を示す。また, 他の殺虫剂に対して感 受性が低下した害虫に対しても感受性の個体群に対するのと 同様に有効である。ささに，本剂は多くの有用昆虫や捕食性 ダニ類などに対する毒性が低く, 優れた選択的殺虫活性を 有することから，総合的害虫管理（IPM）適合資材として認 識され活用されている. 現在, 欧米, アジア, 中近東の十数

\footnotetext{
* 干 665-8555 兵庫県宝塚市高司 4-2-1

E-mail: ikegami@sc.sumitomo-chem.co.jp

(C) 日本農薬学会
}

カ国で登録を取得し, 現地の安定的農作物生産に貢献してい る $^{1-3)}$.

さらに, 当社ではピリダリルの発見後もジハロプロペン化 合物の構造変換を進め, 新たにハダニ類に優れた活性を示す ジハロプロペン化合物を見出した。

本稿では，ピリダリルの発見の経緯をレビューするととも に，新たに見出した殺ダニ活性化合物についても紹介する. また, 当社以外の農薬会社からも本ケミカルクラスの特許出 願が多数なされていることから, 本稿では各社の構造変換に ついても紹介する.

\section{1. リード化合物の創製}

全く新しい化学構造を有する殺虫剂のリード化合物を見出 すために我々が着目したのは, 他社の殺虫剂特許化合物や既 知の殺虫活性物質ではなく, 顕著な殺虫活性は示さないが幼 若ホルモン様作用または抗幼若ホルモン作用を有するとの文

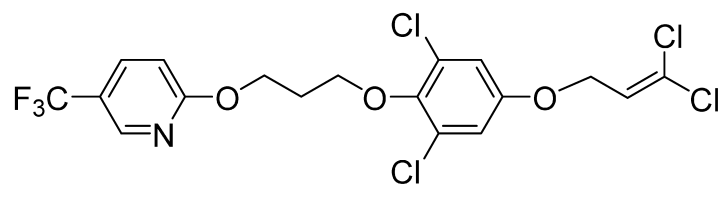

Fig. 1. Chemical structure of pyridalyl. 


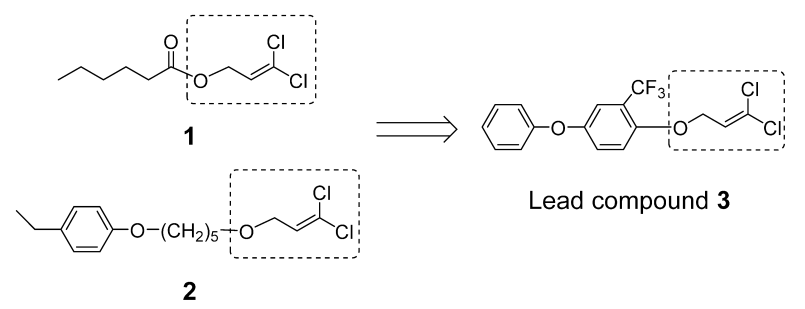

Fig. 2. Discovery of the lead compound 3.

献記載のあったジクロロアリルアルコール誘導体 1 および 2 であった（Fig. 2) ${ }^{4,5)}$. この2つの化合物に共通する3,3-ジク ロロ-2-プロペニルオキシ基という特徵的な部分構造がチョ ウ目幼虫に対する何らかの生理活性に関与しているのではな いか，そして化合物 1 および2のエステルやアルキルエーテ ル構造をより安定なフェニルエーテル構造に変換することに よって活性が発現しやすくなるのではないか，と考えた。そ のような作業仮説の下にいくつかの誘導体を合成した結果， 4-フェノキシ-2-(トリフルオロメチル) フェニル（3,3-ジク ロロ-2-プロペニル）エーテル（Fig. 2, Lead compound 3) がハスモンヨトウ幼虫に対し，500 ppmで死虫率60\%の弱 い殺虫活性を示した．化合物 3 の殺虫活性レベル自体はそれ ほど高いものではなかったが，これまでにない特徵的な症状 を示したことから，この化合物をリード化合物とし構造変換 を行っていくこととした.

\section{2. ピルダリルの発見}

リード化合物 3 は，右側のベンゼン環に3,3-ジクロロ-2-プ

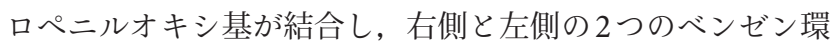
が酸素原子のリンカーで繋がった構造をしている．種々の 構造変換を行った結果, 以下の知見が得られた。3,3-ジクロ ロ-2-プロペニルオキシ基部分には変換の許容性が非常に小 いため，殺虫活性に必須な部分であると考えられる．右側の ベンゼン環については，3位および5位に置換基を有する場 合に特に高い殺虫活性を示す。右側と左側の2つのベンゼン 環の間のリンカー部分の長さの許容性は大きく, 中でも 1,3もしくは1,4-アルキレンジオキシ基が優れた殺虫活性をもた らす．左側のベンゼン環部分は，ピリジン環をはじめ種々の 芳香複素環へ変換することも可能であり，さらに環上には 種々の置換基が許容される。これらの知見をもとに構造最 適化を行い，殺虫活性および効力，安全性，製造コスト等 を考慮し，ピリダリルを開発化合物として選択するに至った (Fig. 3).

ピリダリルはコナガやヨトウ類, タバコガ類などのチョウ 目昆虫に対して特に高い殺虫活性を示す（Table 1）ほか，ミ ナミキイロアザミウマやハモグリバエ類に対しても殺虫活性 を示し，これらの害虫を防除対象とした農薬登録を取得して いる。

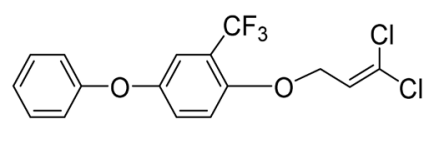

3
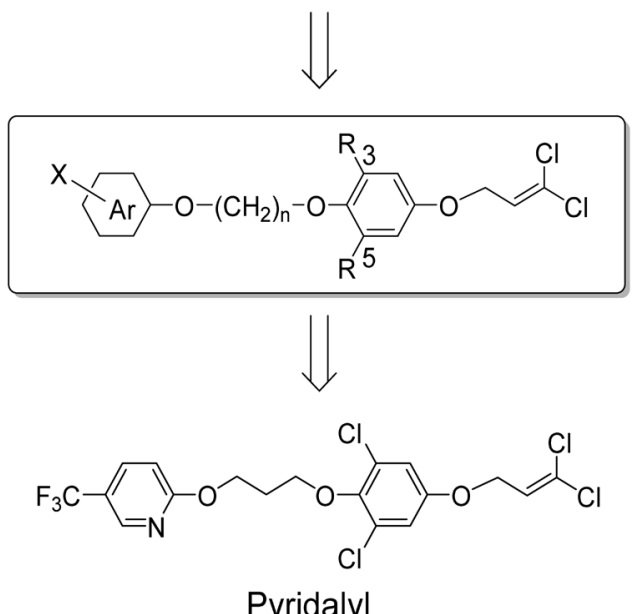

Fig. 3. Structure modification of the lead compound 3 to discover pyridalyl.

Table 1. Insecticidal activity of pyridalyl against lepidopterous pests

\begin{tabular}{|c|c|c|}
\hline Species Stage & Test method & $\begin{array}{c}\mathrm{LC}_{50} \\
(\mathrm{mg}-\text { a.i./L) }\end{array}$ \\
\hline $\begin{array}{l}\text { Cnaphalocrosis medinalis, } \\
\text { 3rd-instar larva }\end{array}$ & Foliar spray & 1.80 \\
\hline $\begin{array}{l}\text { Helicoverpa armigera, } \\
\text { 3rd-instar larva }\end{array}$ & Leaf dip & 1.36 \\
\hline H. $z e a, 2$ nd-instar larva & Leaf dip & 3.23 \\
\hline $\begin{array}{r}\text { Heliothis virescens, } \\
\text { 2nd-instar larva }\end{array}$ & Leaf dip & 4.29 \\
\hline $\begin{array}{c}\text { Mamestra brassicae, } \\
\text { 3rd-instar larva }\end{array}$ & Foliar spray & 1.98 \\
\hline $\begin{array}{c}\text { Spodoptera exigua, } \\
\text { 3rd-instar larva }\end{array}$ & Leaf dip & 0.93 \\
\hline S. litura, 3rd-instar larva & Foliar spray & 0.77 \\
\hline Pieris rapae, 2nd-instar larva & Foliar spray & 3.02 \\
\hline $\begin{array}{l}\text { Plutella xylostella, } \\
\text { 3rd-instar larva }\end{array}$ & Leaf dip & 4.48 \\
\hline
\end{tabular}

${ }^{a)} \mathrm{LC}_{50}$ values were calculated based on the mortality on 5 days after treatment, except for those of P. xylostella which were determined from the mortality on 3 days after treatment.

また，ピリダリルは合成ピレスロイド殺虫剂や有機リン系 殺虫剂, ベンゾイル尿素殺虫剂などに感受性が低下したコナ ガやタバコガ類に対しても感受性の個体群と同様の殺虫活性 を示す (Table 2). 


\section{3. ピリダリル発見後の構造展開}

ピリダリル発見後の構造変換の方向性の一つとして, 左側 の芳香環部分の環構造を鎖状構造へ変換することを試みた. その中で，鎖状のオキシム骨格を持った化合物 $4^{6)}$ (Fig. 4) は, チョウ目昆虫に対してピリダリルに近いレベルの殺虫活 性を示した。この化合物 $\mathbf{4}$ は性能面ではピリダリルを上回る 特徴を見出すことはできなかったものの, ナミハダニに対し て微弱ながら殺ダニ活性を示すことが判明した。そこで，こ の化合物をリードとして，殺ダニ活性を指標にしたスクリー ニングを新たにスタートすることとした。最初に化合物 4 の リンカーのアルキレン鎖をフェニレン基に変換してジフェニ ルエーテル構造にすることによって, ナミハダニに対する活 性が 4 倍以上向上した (Fig. 4, compound $5^{7)}$ ). 次に, 鎖状 のオキシム骨格の部分にピラゾール環を導入することによっ

Table 2. Insecticidal activity of pyridalyl against insecticide resistant strain of P. xylostella (3rd-instar larvae)

\begin{tabular}{llcc}
\hline \multirow{2}{*}{ Insecticide } & Class & \multicolumn{2}{c}{$\mathrm{LC}_{50}(\mathrm{mg}$ a.i./L) } \\
\cline { 3 - 4 } & & $\begin{array}{c}\text { Resistant } \\
\left.\operatorname{strain}^{a}\right)\end{array}$ & $\begin{array}{c}\text { Susceptible } \\
\text { strain }\end{array}$ \\
\hline Pyridalyl & & 2.6 & 4.5 \\
Cyfluthrin & Synthetic pyrethroid & $>500$ & 3.7 \\
Pyrimifos methyl & Organic phosphate & $>450$ & 12.0 \\
Chlorfluazuron & Benzoyl phenylurea & $>25$ & 3.4 \\
\hline
\end{tabular}

${ }^{a)}$ A colony maintained by Sumitomo Chemical Co., Ltd with selection with synthetic pyretroid, organophosphate and benzoylurea insecticides after collection from a cabbage field in Kagoshima in 1991.
て大きなブレークスルーがあり，ナミハダニに対する活性が 市販剂レベルまで向上した (Fig. 4, compound $6^{8)}$ ). 化合物 6の周辺をさらにスクリーニングし，最終的に化合物 $\mathbf{A}^{9)}$ を 見出した（Fig. 4).

\section{4. 化合物 A の生物活性}

化合物 A は, Tetranychus属およびPanonychus属のいずれ のハダニ類に対しても市販剂と同等以上の非常に高い殺ダニ 活性を示した（Table 3).

Table 3. Miticidal activity of Compound A

\begin{tabular}{cccc}
\hline \multirow{2}{*}{ Compound } & \multicolumn{3}{c}{$\mathrm{LC}_{50}\left(\mathrm{mg}\right.$ - a.i./L) ${ }^{a)}$} \\
\cline { 2 - 4 } & Tetranychus urticae & Panonychus citri & Panonychus ulmi \\
\hline Compound A & 0.29 & 0.66 & 1.15 \\
Tebufenpyrad & 0.59 & 0.95 & 1.34 \\
\hline
\end{tabular}

${ }^{a)} \mathrm{LC}_{50}$ values were calculated based on the mortality of adult females at 5 days after treatment.

Table 4. Miticidal activity of Compound A against a miticide resistant strain of T. urticae (adult)

\begin{tabular}{cccc}
\hline \multirow{2}{*}{ Compound } & \multicolumn{3}{c}{$\mathrm{LC}_{50}\left(\mathrm{mg}\right.$ - a.i./L) ${ }^{a)}$} \\
\cline { 2 - 4 } & $\begin{array}{c}\text { Resistant } \\
\text { strain }\end{array}$ & $\begin{array}{c}\text { Susceptible } \\
\text { strain }\end{array}$ & $\mathrm{R} / \mathrm{S}$ ratio \\
\hline Compound A & 0.36 & 0.29 & 1.24 \\
Tebufenpyrad & 99.9 & 0.59 & 169 \\
\hline
\end{tabular}

${ }^{a)} \mathrm{LC}_{50}$ values were calculated based on the mortality of adult females at 5 days after treatment.<smiles>Fc1ccc(OCCCOc2c(Cl)cc(OCC=C(Cl)Cl)cc2Cl)nc1</smiles>

Pyridalyl<smiles>CC(COCCCCCOc1c(Cl)cc(OCC=C(Cl)Cl)cc1Cl)NOC(C)(C)C</smiles>

4<smiles>C#CC=C</smiles><smiles>CONC(COc1ccc(Oc2ccc(OCC=C(Cl)Cl)cc2)cc1)C(C)(C)C</smiles>

5

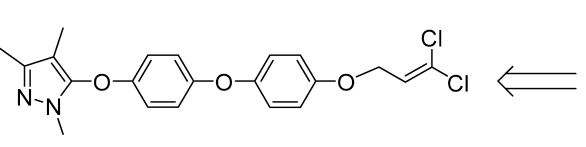

Compound A

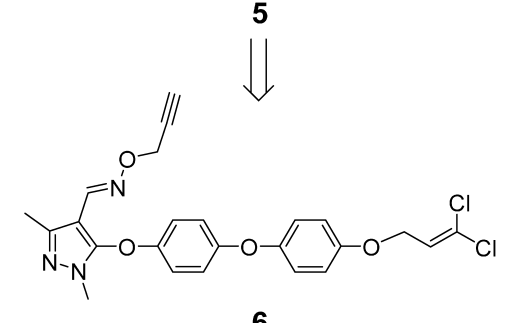

6

Fig. 4. Structure modification of pyridalyl to discover the miticidal compound $\mathbf{A}$. 
さらに：トコンドリア電子伝達系複合体I阻害剂 (METI）のテブフェンピラド，フェンピロキシメートをは じめ, ダニ類成育阻害剂のへキシチアゾクスなどの各種の薬 剂に感受性が低下した抵抗性系統のナミハダニに対しても, 化合物 $\mathbf{A}$ は感受性の個体群と同様の殺ダ二活性を示した (Table 4). 現時点で, 化合物 $\mathbf{A}$ の作用機構は明らかになっ ていないが，既存の殺ダ二剂とは異なる新たな作用機構で殺 ダ二活性が発現している可能性があることから，その解明が 期待される。

\section{5. 各社の構造展開}

当社では多くの研究員がジハロプロペン殺虫剂の構造改 変に関わり，これまでに十数件の特許出願を行っている。一 方で，本系統は既存剤とは異なる新しいケミカルクラスであ ることから, 当社以外の農薬会社からも数十件にのぼる多数 の特許出願がなされてきている. それらの構造変換の方向性 は，（a）左側の芳香環部分の縮合複素環への变換，（b）複素 環のさらなる導入，および（c）右側ベンゼン環部分の骨格

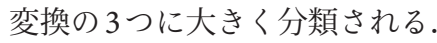

ピリダリルの左側の芳香環部分を縮合複素環に变換した化 合物の例を Fig. 5 にまとめた. 縮合複素環としては, ジヒド ロベンゾフラン環 ${ }^{10)}$, ベンズオキサゾール環 ${ }^{11,12)}$, キノキサ リン環 ${ }^{13)}$ 等が挙げられる.

分子内に複素環がさらに導入された化合物の例を Fig. 6 に まとめた。複素環としては, イソキサゾール環 ${ }^{14)}$, テトラ ゾール環 ${ }^{15)}$, オキサジアゾロン環 ${ }^{16)}$, トリアゾロン環 ${ }^{17)}$, 1,2,3-トリアゾール環 ${ }^{18)}$, およびピラゾール環 ${ }^{19)}$ 等が挙げら れ，主にリンカー部分に挿入されるか，あるいは左側の芳香 環上の置換基として導入されている.

右側ベンゼン環部分は，ピリダリルではパラ配置のヒドロ キノン構造であるが，その部分を他の構造に変換した化合物 もいくつか特許出願されている. Fig. 7 にまとめたように,

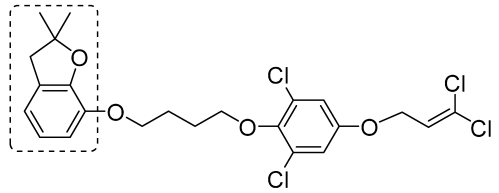

WO2004/098283

(FMC)

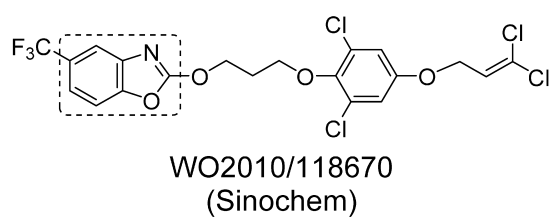

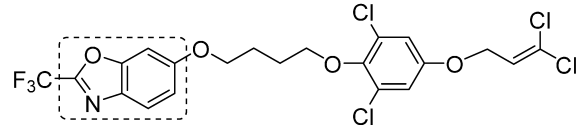

WO2004/099105 (FMC)

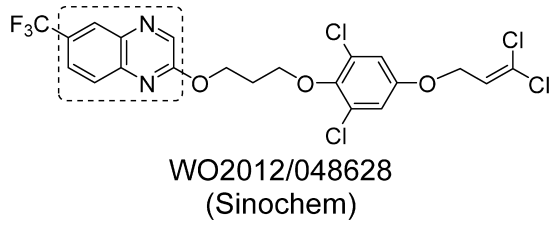

Fig. 5. Modifications of the pyridine ring of pyridalyl to a fused heterocycle.

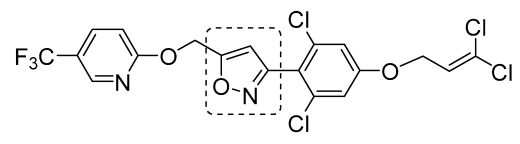

W001/44154

(Mitsubishi)

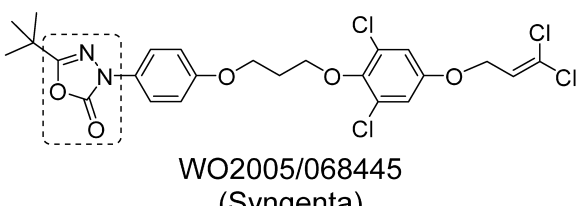

(Syngenta)

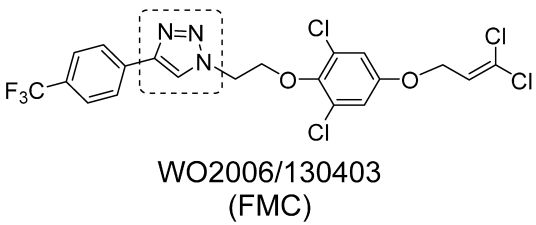

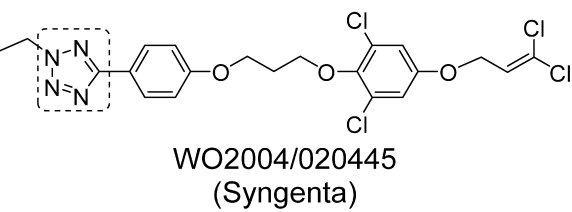

(Syngenta)

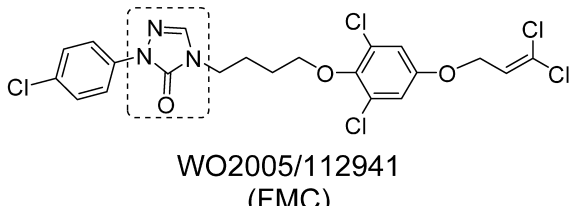

(FMC)

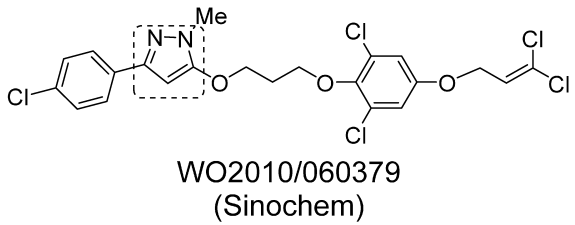

Fig. 6. Addition of one more heterocylic ring to pyridalyl derivatives. 


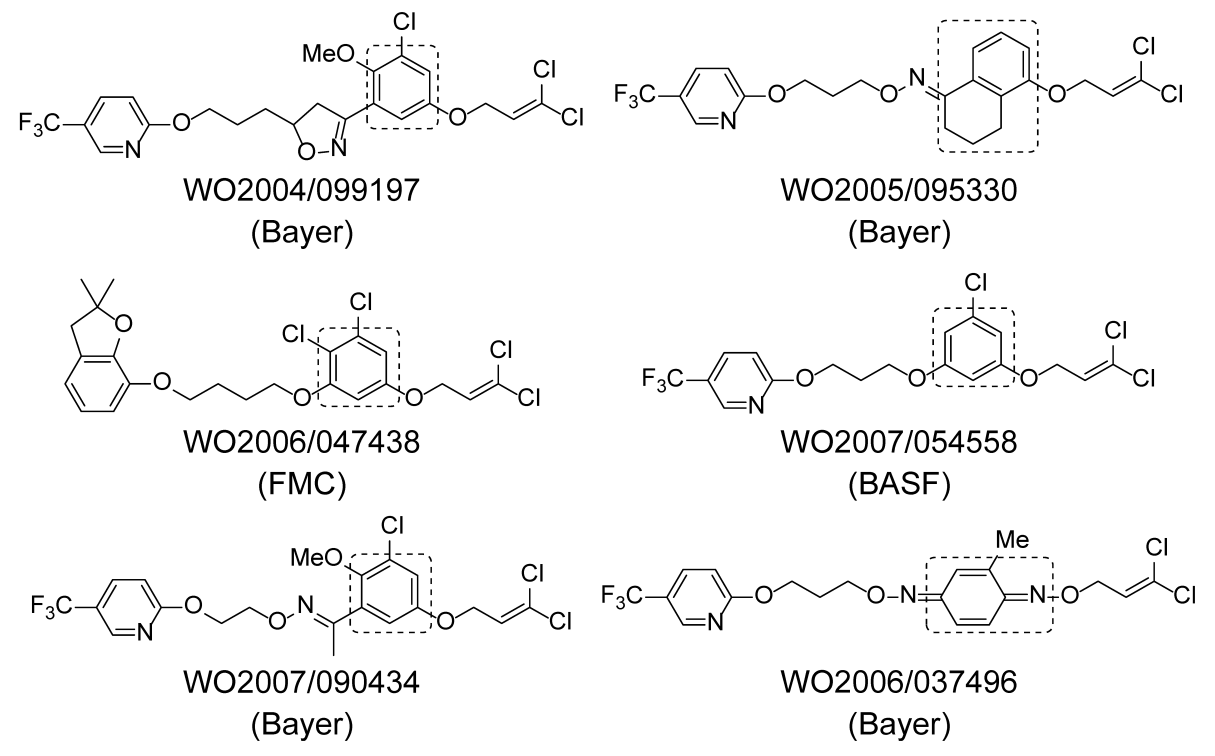

Fig. 7. Modifications of the right side benzene ring of pyridalyl derivatives.

パラ配置からメタ配置への変換 ${ }^{20-24)}$ とヒドロキノン構造か らキノンオキシム構造への変換 ${ }^{25)}$ が主なものである.

このように，各社により新しいジハロプロペン化合物 が種々見出されてきているが, いずれの化合物も3,3-ジ八 ロ-2-プロペニルオキシ構造を保持しており, この部分が活 性発現にとって必須であるという我々の見解を支持するもの となっている.

\section{おわりに}

当社で見出したピリダリルおよび殺ダニ活性化合物の創製 について述べてきた。これらに共通するのは, 非常に微弱 な活性のヒット化合物に着目し，それがリード化合物として 有効かどうかを検証しながら, 地道に合成と活性評価を繰り 返していく手法である。このような手法に挑戦したピリダリ ルは，既存の殺虫活性物質をリードにしてそれを改良してい く手法に比べ, 探索にも開発にも多大な時間を要したが, 欧 米, アジア, 中近東の十数力国で登録を取得し, 現地の安定 的農作物生産に貢献している. それゆえ, 既存の殺虫剤とは 異なる作用機構を持った新しい殺虫剂の創製にチャレンジし 続けていくことは, 今後も我々創農薬研究者の大きな使命の ひとつであると考えている.

\section{引 用 文 献}

1) N. Sakamoto, S. Saito, T. Hirose, M. Suzuki, S. Matsuo, K. Izumi, T. Nagatomi, H. Ikegami, K. Umeda, K. Tsushima and N. Matsuo: Pest Manag. Sci. 60, 25-34 (2003).

2) S. Saito, S. Isayama, N. Sakamoto, K. Umeda and K. Kasamatsu: Proc. Brighton Crop Prot. Conf.-Pests Dis. 1, 33-38 (2002).
3) 坂本典保, 広瀬太郎, 齋藤 茂, 梅田公利：農薬誌 37, 283-287 (2012).

4) G. B. Quistad, D. C. Cerf, S. J. Kramer, J. B. Bergot and D. A. Schooley: J. Agric. Food Chem. 33, 47-50 (1985).

5) P. Piccardi, P. Massardo, F. Bettarini and A. Longoni: Pestic. Sci. 11, 423-431 (1980).

6) H. Ikegami, K. Izumi, M. Suzuki, N. Sakamoto and S. Saito (Sumitomo Chemical Co., Ltd.): PCT Int. Appl. WO1998/045254 (1998).

7) 池上宏, 鈴木雅也（住友化学工業株式会社）：特開2001335550 (2001).

8) M. Hashizume, N. Sakamoto and H. Takyo (Sumitomo Chemical Co., Ltd.): PCT Int. Appl. WO2004/085405 (2004).

9) H. Takyo, M. Hashizume and N. Sakamoto (Sumitomo Chemical Co., Ltd.): PCT Int. Appl. WO2005/075433 (2005).

10) G. Theodoridis, E. L. Barron, D. P. Suarez, Y. L. Zhang, P. Ding, D. M. Roush, S. F. Donovan, F. J. Zawacki, W. H. Yeager, J. W. Lyga and D. H. Cohen (FMC Corp.): PCT Int. Appl. WO2004/098283 (2004).

11) G. Theodoridis, E. J. Barron, D. P. Suarez, L. Y. Zhang, P. Ding, J. W. Lyga and M. P. Whiteside (FMC Corp.): PCT Int. Appl. WO2004/099105 (2004).

12) B. Li, A. Guan, J. Wang, Y. Qin, H. Zhang, H. Yu and S. Liang (Sinochem Corp., Shenyang Research Institute of Chemical Industry Co., Ltd.): PCT Int. Appl. WO2010/118670 (2010).

13) B. Li, A. Guan, J. Wang, X. Chang, S. Liang, Y. Song and L. Lv (Sinochem Corp., Shenyang Research Institute of Chemical Industry Co., Ltd.): PCT Int. Appl. WO2012/048628 (2012).

14) M. Katsurada, S. Kawata, Y. Shiga, T. Fukuchi and R. Yamada (Mitsubishi Chemical Corp.): PCT Int. Appl. WO2001/044154 (2001).

15) W. Zambach, A. Steiger, P. Renold, S. Trah and R. G. Hall (Syngenta Participations AG): PCT Int. Appl. WO2004/020445 (2004). 
16) R. G. Hall, S. Trah, W. Zambach and J. Tuleja (Syngenta Participations AG): PCT Int. Appl. WO2005/068445 (2005).

17) E. J. Barron, L. Y. Zhang, J. W. Lyga and M. P. Whiteside (FMC Corp.): PCT Int. Appl. WO2005/112941 (2005).

18) J. W. Lyga, F. Zawacki and L. Y. Zhang (FMC Corp.): PCT Int. Appl. WO2006/130403 (2006).

19) C. Liu, M. Li, J. Wang, J. Zhang, H. Zhang, S. Hao, J. Zhang and J. Yang: (Sinochem Corp., Shenyang Research Institute of Chemical Industry Co., Ltd.): PCT Int. Appl. WO2010/060379 (2010).

20) P. Jeschke, M. Müller, I. Escher, O. Malsam, K.-J. Haack, R. Braun and C. Arnold (Bayer Cropscience AG): PCT Int. Appl. WO2004/099197 (2004).

21) N. Sasaki, N. Toshima, K. Domon, K. Araki, Y. Otsu, K. Shibuya and E. Shimojo (Bayer Cropscience AG): PCT Int. Appl. WO2005/095330 (2005).

22) I. Escher, M. Müller, P. Jeschke, M. Beck, O. Gaertzen, O. Malsam, P. Lösel, U. Ebbinghaus-Kintcher, C. Arnold and K.-J. Haack (Bayer Cropscience AG): PCT Int. Appl. WO2004/099197 (2004).

23) E. J. Barron, Y. L. Zhang, F. J. Zawacki, J. W. Lyga and G. Theodoridis (FMC Corp.): PCT Int. Appl. WO2006/047438 (2006).

24) M. Puhl, M. Kordes, M. Pohlman, N. Götz, M. Rack, J. Lange- wald, F. Schneider, D. D. Anspaugh, D. L. Culbertson, H. Oloumi-Sadeghi and D. G. Kuhn (BASF AG): PCT Int. Appl. WO2007/054558 (2007).

25) N. Sasaki, K. Domon, M. Ito, K. Shibuya, E. Shimojo, A. Emoto and P. Jeschke (Bayer Cropscience AG): PCT Int. Appl. WO2006/037496 (2006).

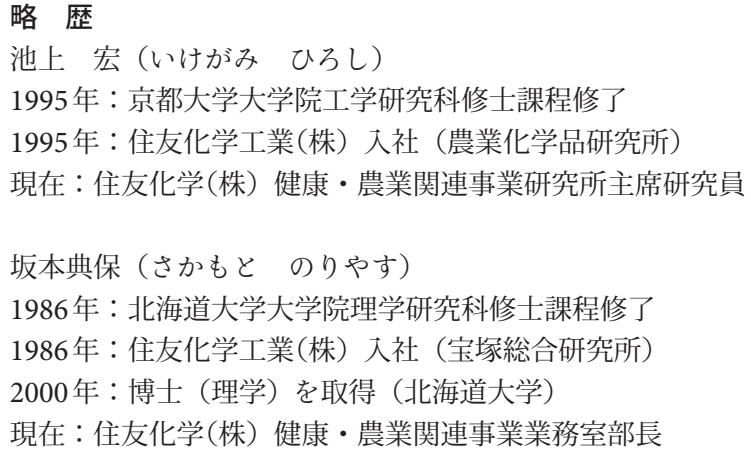

